\title{
Dural ectasia: a manifestation of type 1 neurofibromatosis
}

\section{Colin Yi-Loong Woon MBBS MMed(Ortho)}

Previously published at www.cmaj.ca

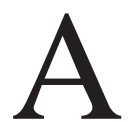

43-year-old woman was referred for unusual pelvic ultrasonographic findings of septated cystic structures in both flanks, seen while she was undergoing assessment for uterine fibroids. She had type 1 neurofibromatosis (von Recklinghausen disease) with a remote history of anterior fusion of the L1 to L3 vertebrae for unstable dystrophic kyphosis. There was no family history of type 1 neurofibromatosis.

On examination, the patient showed neurocutaneous stigmata of type 1 neurofibromatosis, including multiple neurofibromas, axillary freckling and prominent café au lait spots. Magnetic resonance imaging of the spine showed marked dural ectasia (Figure 1, Appendix 1, available at www.cmaj .ca/cgi/content/full/cmaj.092004/DC1). Because she had neither back pain nor neurologic deficit at the time of presentation, no surgical intervention was performed.

Dural ectasia, widening of the dural sac, is associated with the dystrophic changes found in type 1 neurofibromatosis and appears as dural outpouchings (meningoceles) through enlarged neuroforamina, leading to erosion of surrounding bone and displacement of adjacent organs, as in this patient. Up to $70 \%-80 \%$ of dural ectasia is found in patients with type 1 neurofibromatosis, ${ }^{1}$ although it is also associated with Marfan syndrome (in up to $92 \%$ ), ${ }^{2}$ EhlersDanlos syndrome, ankylosing spondylitis and achondroplasia, and can occur idiopathically. ${ }^{3}$ Meningioma and spinal nerve fibroma are associated with type 1 neurofibromatosis, and are also capable of protruding laterally through and eroding the neuroforamina. Classic radiologic findings include erosion of the central posterior vertebral body, wedging and posterior scalloping of the vertebral body, pedicle erosion, foraminal enlargement and kyphosis.

The complications of progressive vertebral body erosion include angular deformities (usually fewer than six vertebral levels) and vertebral fractures and dislocations. Neurologic deficit rarely occurs because the spinal canal is widened. ${ }^{4}$ These deformities have been known to progress and evolve during the course of disease, a phenomenon known as "modulation." ${ }^{5}$ Patients with dystrophic changes

From the Department of Orthopaedic Surgery, Singapore General Hospital, Singapore

\section{CMAJ 2010. DOI:10.1503/cmaj.092004}

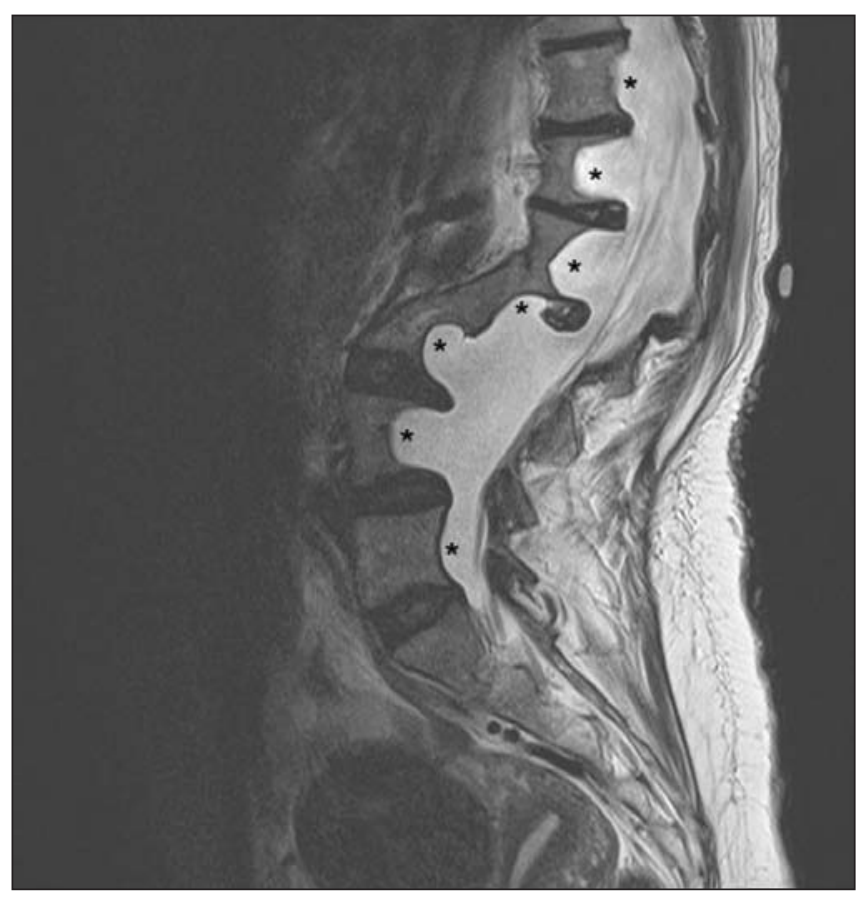

Figure 1: Sagittal $T_{2}$-weighted spin-echo magnetic resonance image of the lumbosacral spine of a 43-year-old woman showing posterior vertebral scalloping by dural ectasia (asterisks).

should be observed closely for progression. Early surgical stabilization may be necessary to prevent severe deformity and late complications.

This article has been peer reviewed.

Competing interests: None declared.

\section{REFERENCES}

1. Gajeski BL, Kettner NW, Awwad EE, et al. Neurofibromatosis type I: clinical and imaging features of von Recklinghausen's disease. J Manipulative Physiol Ther 2003;26:116-27.

2. Fattori R, Nienaber CA, Descovich B, et al. Importance of dural ectasia in phenotypic assessment of Marfan's syndrome. Lancet 1999;354:910-3.

3. Toyoda K, Taguchi T, Kaneko K, et al. High-grade L5 spondylolisthesis associated with dural ectasia in neurofibromatosis. J Orthop Sci 2005;10:233-6.

4. de Kleuver M, van Jonbergen JPW, Langeloo DD. Asymptomatic massive dural ectasia associated with neurofibromatosis type 1 threatening spinal column support: treatment by anterior vascularized fibular graft. J Spinal Disord Tech 2004;17:539-42.

5. Durrani AA, Crawford AH, Chouhdry SN, et al. Modulation of spinal deformities in patients with neurofibromatosis type 1. Spine 2000;25:69-75. 